'This article may not exactly replicate the final version published in the APA journal. It is not the copy of record.' 


\title{
Passing the time when in pain: investigating the role of
}

\section{musical valence}

\begin{abstract}
The effective management of pain outside of clinical settings represents a significant challenge to health services. Music listening has been successfully used as a method of pain management, with the greatest benefits to listeners evident if the music is familiar, preferred and has emotional resonance. This study examined the role of self-selected emotion-inducing music used for pain management (pain tolerance, intensity, perceived control, distraction and anxiety reduction) during the cold pressor test. In a repeated-measures design, four cold pressor tests were used to induce short-term, acute pain, whilst 41 participants listened either to happy, sad, relaxing or no music. Findings indicated that music enhanced pain tolerance over no music, and happy and relaxing music increased pain tolerance and altered time perception to a greater extent than sad music. Happy and relaxing music facilitated distraction from pain and enhanced perceived pain control. Relaxing music additionally had anxiolytic properties and reduced pain intensity. Results suggest that music's inclusion in pain management is justified and that music with happy and relaxing components can be used to facilitate coping with pain in a non-clinical context.
\end{abstract}

\section{Keywords}

Perceived control, distraction, pain relief, analgesia 
Pain greatly influences daily life, interrupting and limiting daily functioning (Abu-Saad, 2010; Cordell et al., 2002; Hasselström, Liu-Palmgren \& Rasjo-Wraak, 2002), which in turn can cause emotional stress (Tjakke, Reinders, Tenvergert \& Stegenga, 2010). Self-initiated pain management in the context of a home-based environment is considered an important aspect of self-care (Andersson, Ejlertsson, Leden, \& Scherstén, 1999). Beyond pharmacological approaches, the use of distraction techniques is thought to be beneficial as an adjunctive method of self-care (McCaul \& Malott, 1984). Interactive distraction methods, such as video games, virtual reality or card games, have been found to be distractors of sufficient magnitude for pain management for those suffering from laboratory-induced, acute pain (Wohlheiter \& Dahlquist, 2013). Similarly, relaxation approaches are commonly used and taught in clinical settings (see Chen \& Francis, 2010; Mohammadi, Rafii, \& Jamshidi, 2013; Rejeh, Heravi-Karimooi, Vaismoradi \& Jasper, 2013). However, both interactive distraction and taught relaxation techniques require significant resources, either in terms of technology and materials, or clinical expertise. There is therefore a need to identify self-care approaches which are low-cost and easily applicable by people suffering with severe acute pain, without requiring additional clinical training.

Research has suggested an alternative method which is both an effectively engaging distractor and has relaxing properties, that is, music listening (Good, 1996; Good et al., 1999). Music listening can be active and focused, or passive, background listening, both of which may potentially be used for pain management and self-care (Finlay \& Rogers, 2014). This method can be used for a long period of time, is easily available, needs no professional support, and is cost-effective (Vaajoki, Pietilä, 
Kankkunen \& Vehviläinen-Julkunen, 2012). Music listening has been shown to help increase pain tolerance in patients, and enhances perceived control of pain (Misic, Arandjelovic, Stanojkovic, Vladejic \& Mladenovic, 2010; Vaajoki et al., 2012). For example, Guétin et al (2012) found that music listening helped patients with chronic pain to increase their pain tolerance and manage their anxiety and depression. Music listening may therefore offer a beneficial and promising strategy for patient-initiated self-care. It is important, however, to ensure that the complexity of such an intervention is fully understood in reference to the appropriateness of the music chosen, individuals' music preferences and the emotional resonance of the music itself. Whilst it is known that music listening can impact upon both acute and chronic pain, limited evidence addresses how the valence and emotional resonance of the music influences the outcomes of such interventions (Roy, Peretz, \& Rainville, 2008; Silvestrini, Piguet, Cedraschi, \& Zentner, 2013; see only Zhao \& Chen, 2009). The music and pain literature which does consider valence or emotional resonance, typically looks only at a limited palate of dichotomous musical valences (e.g. happy vs. sad or pleasant vs. unpleasant): there is consequently a need to further investigate the gradation and differentiation that may exist within this issue.

Simply listening to music may not be sufficiently effective for managing pain if the music is not enjoyable for the listener. It is possible that the more likeable the music is to the individual, the better the effects of music listening on the pain (following Hargreaves \& North, 1997; MacDonald, Miell \& Hargreaves, 2002). For example, Wright and Raudenbush (2010) examined pain tolerance in young and older participants whilst listening to classical music. It was found that older participants rated classical 
music as more preferable, when compared against ratings by younger participants. Older adults also reported being more distracted by classical music and better able to tolerate pain than did younger participants. Similarly, Mitchell and MacDonald (2006) found that their participants controlled pain substantially better when listening to their preferred music compared to non-preferred music, again showing that preference plays an important role in managing pain during music listening. Thus, if an individual uses music listening as a method to reduce the biopsychosocial distress caused by pain, then the music chosen must be enjoyable to the individual themselves in order to be able to experience the full effects of music listening. Thus it is important for participants to utilize their preferred music, in the context of investigating the collective influence of musical valence and emotion on acute pain.

Emotions are an integral part of everyday life (Chartrand et al., 2006; George \& Brief, 1992; Georgel \& Jones, 1997), and emotion and pain are closely tied together in a cyclical relationship, with emotions impacting pain intensity and tolerance, and vice versa (Keefe, Lumley, Anderson, Lynch, \& Carson, 2001). Tang et al (2008) found that a negative mood state increased self-reported pain intensity and decreased pain tolerance, while a positive mood reduced self-reported pain intensity and increased pain tolerance. Similarly, van Laarhoven et al. (2012) found pain intensity was heightened by a negative mood when compared with a pleasant mood. Consequently pain management approaches must be evaluated in association with emotional factors, and it is possible that emotions may be harnessed to enhance the benefits of patient-initiated self-care.

Pain is highly engaging of emotions, and research has argued that music is also strongly emotionally resonant (Juslin \& Sloboda, 2009). Krahé and Bieneck (2012) asked 
participants to listen to music rated as pleasant or aversive by an independent sample. They found that participants in a pleasant music condition were in a more positive mood than those in the aversive music condition and those in the pleasant music condition also experienced less anger and displayed less aggression. However, it is debated whether the perceived emotions expressed in the music (for example, whether the music is predominantly happy or sad) actually have an effect on personally-experienced emotions (Konečni, 2008). With music labelled as happy, there is confirmatory research evidence to show that such music typically does evoke feelings of happiness (Konečni, Brown \& Wanic, 2008). However, music renders a wide range of emotions and it should be noted that the desired emotions may not always be successfully experienced by the participant as such (Konečni, 2008). For example, in listening to sad music, though participants perceive the music as being sad, it may not be experienced as sad (Kivy, 1989; 1990). In other words, participants may recognise that a piece of music has a sad tone but may not necessarily experience sadness when listening to the music. Kawakami, Furukawa, Katahira and Okanoya (2013) found participants felt more lethargic and unmotivated when listening to music labelled as sad. Vuoskoski and Eerola (2012) argue that it is not the tone of the music that is a factor, but the listener's autobiographic memories connected with the music. Vuoskoski and Eerola found that participants who connect a negative experience or an undesirable person with a piece of music, regardless of the tone, are more likely to feel sad. Therefore individuality of choice must be prioritized when inducing sadness.

Music is often employed by listeners for emotion management; people tend to listen to sad music deliberately (Kivy, 2002: Levinson, 1990). Schellenberg, Peretz and 
Vieillard (2008) explain this phenomenon could be due to a desire to self-manage general anxiety or fatigue from day-to-day stressors: individuals experiencing a negative mood listen in order to relate to the music and diminish stress. However, Ladinig and Schellenberg (2012) found that participants generally liked music which made them feel happy, and disliked music which made them feel sad. Gatewood (1927) argued that what matters is not the emotion in the music but the strength of the emotion aroused in the person when listening to music. Individuals prefer listening to music that stimulates heightened emotions, because the music either holds meaningful autobiographic memories, or it strongly relates to them. Participants' preferences and the activation of subjective emotion must therefore be prioritized in audio-analgesia research.

Pain management research has demonstrated the benefit of positive emotion in enhancing patient perceptions of control and self-management of their pain (see Tang et al., 2008; van Laarhoven et al., 2012, for examples). Therefore, music that heightens positive emotions (e.g. happiness) represents a logical target as the potentially preferred choice for music-induced analgesia. However, to assume that positive music is better than the potentially cathartic value of sad music seems overly simplistic. Previous research has addressed this area, but has tested the relationship between emotion, music and pain to a lesser extent. For example, Roy, Peretz and Rainville (2008) investigated the effects pleasant and unpleasant music had on pain intensity, and found that pleasant music reduced pain intensity to a greater extent than unpleasant music. However, this study did not measure the intensity of the music-induced emotions in participants, nor did participants choose their own music; it was pre-selected by the experimenters. Zhao and Chen (2009) investigated sad and happy music of equal likeability by participants, and 
found both types of music contributed towards reduced pain intensity. However, participants were again unable to select their music, a factor fundamental to maximizing the benefits of the intervention (Mitchell, MacDonald, \& Brodie, 2006).

Relaxing music represents an alternative to happy or sad music, and is an approach widely used by therapeutic or alternative medicine practitioners for perceived physiological benefits (Davis \& Thaut, 1989). Similar to other musical valences, relaxation is enhanced when participants choose the music themselves (Tan et al., 2012). This functions in combination with other factors: Tan, Yowler, Super and Fratianne (2012) found that the more familiar a person is with the music they are listening to, the more relaxing the music will be to the listener. Therefore by harnessing familiarity and preference, individuals may be able to relax further, which helps manage pain-related distress, anxiety and depression (Bell \& Meadows, 2013; Lauche et al., 2013; Mohammadi et al., 2013). To date, there is little evidence to show which type of music would be more effective for music listening for pain management: happy or relaxing music, or sad music through catharsis.

Managing pain through music-induced analgesia is principally thought to be a function of enhanced pain tolerance (Mitchell \& Macdonald, 2006): by distracting the individual in pain through music, their perception of time is altered and pain tolerance increased, through increasing the amount of time that the listener can cope with pain (Finlay \& Rogers, 2014). Listener perception of the passing of time is a key factor, as slowing or speeding time perception can impact upon pain tolerance (Litt, 1988). Research has found that time passes faster while listening to music (Droit-Volet, Bigand, Ramos \& Bueno 2010), and such a mechanism may distort the perception of time spent 
attending to pain, affecting pain tolerance. Through music, preference and emotional resonance both impact on time perception: the passage of time is perceived to be faster when an individual is listening to music that they have chosen (Cassidy \& MacDonald, 2010).

Time perception is also affected by musical valence: Yamada and Kawabe (2011) found that aversive emotional stimuli extended the passage of time compared with pleasant stimuli, which perceptually accelerate an internal clock. Therefore, feelings of relaxation help increase perceived pain control, speeding the perceived passage of time so that time spent enduring pain feels reduced (Chavez, 2004), though the lived passage of time is experienced slowly (at a relaxed pace; Polaino-Lorente, 1977). Ultimately, online judgements of time passing, moment-to-moment, may differ from retrospective, post-hoc perceptions of time having passed. It seems, therefore, that valence and preference work in conjunction through music, together harnessing and altering the sensation of passing time and changing perceptions of control over pain. There is a need to consider time through actual and perceived pain tolerance estimations, in order to fully understand the contribution of music to the sensory and affective experience of pain.

This study aimed to investigate the role of preferred music, selected for its perceived emotional components, in enhancing acute, laboratory-induced pain management. Participant-selected happy, sad and relaxing music was compared against no music during a pain induction procedure using the cold pressor test, with healthy volunteers. It was expected that all musical valences would facilitate tolerance of pain in comparison with a no music condition. It was hypothesised that they would show ranked outcomes: happy music would consistently show advantages over relaxing music, with 
sad music showing only minimal benefits in comparison with no music. It was expected that all outcomes would model this ranking: therefore happy music would enable participants to feel they could tolerate their pain and reduce their anxiety to the greatest extent, with relaxing music also showing positive, but less pronounced benefits. Sad music was expected to facilitate pain tolerance and anxiety reduction to a lesser extent than the other musical valences, but still to show marginal benefit over no music. It was also hypothesized that happy music would have the largest effect on level of distraction away from pain, functioning as the most absorbing valence of musical stimulus. Research has suggested that the sensory dimension of pain is less impacted than the affective dimension through music-induced analgesia (Mitchell \& MacDonald, 2006), therefore no directional findings were expected in relation to pain intensity.

\section{Method}

\section{Participants}

Forty-one healthy volunteers were recruited from the University of Buckingham (24 females, 17 males). The mean age of participants was 25.98 ( $\mathrm{SD}=9.095$; range 1859 years). Individuals with diabetes, circulatory disorders, chronic pain, or low/high blood pressure were excluded.

Ethical approval was provided by the School of Science Ethics Committee at the University of Buckingham. Participants were informed that their participation was voluntary, and that they could withdraw from the study at any time without reason. Written, informed consent was obtained from all participants after they were briefed via participant information sheet and opportunity for questions was provided. Full debriefing 
was provided at the conclusion of the study. If any participants experienced side-effects, they were asked to contact their GP.

\section{Design}

A repeated-measures within-subjects design was used, investigating the impact of music type (4 levels; happy, sad, relaxing or no music) on outcome measures. Primary outcome measures were pain intensity, pain tolerance and perceived pain tolerance. Secondary outcome measures were pain-related anxiety, distraction from pain and perceived control of pain. Order of music presentation was randomized following the baseline no music trial.

\section{Stimuli and Apparatus}

Standardised and commercially-available music and pain-induction equipment was used:

Circulatory water bath. A JeioTech circulatory water bath (Model RW-3025G, Medline Scientific, UK) was used with circulating water, cooled to $0^{\circ} \mathrm{C}$. Consistency in water temperature is important for comparable and reliable results (Mitchell, MacDonald, $\&$ Brodie, 2004). The maximum length of time participants were permitted to keep their hand in the water was 240 seconds (4 minutes; following Jackson et al., 2005). The cold pressor test is a reliable and effective method of inducing short-term pain (Rutchick \& Slepian, 2013).

Music selection. Participants provided their own music, chosen specifically for perceived happy, sad and relaxing valence. Music was provided either on CD or digital 
download.

\section{Materials: Primary Outcome Measures}

Short-Form McGill Pain Questionnaire (SFMPQ-2; Melzack, 1987). A 15 item questionnaire investigating pain intensity through sensory and affective components of pain. This has been found to be a reliable and valid questionnaire to measure selfreported pain (Sun et al., 2010).

Pain Tolerance (PT). This was calculated as the timespan between initial immersion of hand into the water, and when participants withdrew their hand, measured in seconds (following Duschek et al., 2008; Mitchell et al., 2008), providing an 'online', objective measure of pain tolerance. Edwards, Doleys, Fillingim and Lowery (2001) report that pain tolerance provides a quantitative benchmark for objective evaluation of pain.

Perception of Pain Tolerance (PPT). A self-reported estimate of the amount of time participants felt they retained their hand in the water during each cold pressor test (in seconds). This represents a retrospective subjective judgement of participants' own ability to tolerate pain through an estimate of time having passed.

\section{Materials: Secondary Outcome Measures}

General Self-Efficacy Questionnaire (GSE; Schwarzer and Jerusalem, 1995). A well-validated 10-item measure of pain-related self-efficacy (Luszczynskaa et al., 2005) 


\section{State-Trait Anxiety Inventory (STAI; Spielberger, Gorsuch, Lushene, Vagg}

\& Jacobs, 1983). A 20-item questionnaire assessing state and trait dimensions of anxiety. The STAI has been widely used in clinical research (Barnes, Harp \& Jung, 2002).

\section{Materials: Numerical rating scales (NRS; Jensen \& Karoly, 2001)}

Eight 11-point numerical rating scales were used:

Current Pain. This measured the pain that the participant is in before using the cold pressor test using the end-points $(0=$ no pain and $10=$ worst possible pain $)$.

Familiarity. A measurement of familiarity with the participant-selected musical choices using the end-points $(0=$ not at all familiar, $10=$ extremely familiar $)$.

Likeability. A measurement of likeability assessing preference for the musical choice (ranging from $0=$ disliked and $10=$ extremely well-liked).

Emotion (happy, sad, and relaxed). Three NRS measuring the intensity of emotion for each type of music $(0=$ not happy/sad/relaxed and $10=$ extremely happy/sad/relaxed).

Anxiety. A measure of general anxiety using the end-points $0=$ not at all anxious and $10=$ extremely anxious . 
Pain Intensity. An assessment of present pain intensity before and after each trial (end-points as with current pain)

Distraction. A measure of distractedness in response to the music listening interventions $(0=$ not distracted at all and $10=$ extremely distracted $)$.

Perceived Control of Pain. A measure of perceived control of pain during each cold pressor trial $(0=$ no control at all, $10=$ complete control $)$.

\section{Procedure}

Participants who chose to take part were screened for exclusion criteria and provided written, informed consent. All participants were included in the trial as none reported conditions necessary for exclusion. On attendance at the laboratory, participants were asked to remove all time devices (watches), and all were removed from sight to avoid bias in time duration judgments. Participants were asked to provide three (happy, sad, relaxing) self-selected pieces of music in either $\mathrm{CD}$ or digital format. Participants then completed baseline questionnaires (STAI; SF-MPQ; GSE; current pain, familiarity, likeability and anxiety NRS) and their pre-test hand temperature was measured via digital thermometer. This temperature was then used to return their dominant arm to baseline temperature between each cold pressor trial. Participants then completed a no music trial to provide a comparative condition. Post-test data was collected for emotion, pain perception, pain intensity, anxiety, distraction and control NRSs. Pain tolerance was 
timed during the trial and perception of pain tolerance (in seconds) was requested. All post-test ratings were scored verbally to allow the dominant arm to return to baseline temperature. All interactions with the experimenter were scripted to control for potential experimenter bias. The participant then completed three further cold pressor trials, counterbalanced in terms of presentation of music (happy, sad or relaxed), with post-test ratings and timings again provided after each test. All music was repeated immediately if it was finished before the 240 seconds ( 4 minutes) cold pressor time limit, ensuring there were no non-music gaps within each experimental condition. Between trials recovery time was provided for as long as needed for hand temperature to return to baseline using a hot water bottle and warm cloth. After all trials, participants answered a question regarding during which trial they found the pain the most tolerable.

\section{Statistics and Analysis}

Repeated-measures ANOVAS were used to assess the outcome measures. HuynhFeldt corrections were applied if sphericity was violated (following Girden, 1992). Bonferroni pairwise comparisons were subsequently applied. Perception of Pain tolerance was compared against Pain Tolerance using a paired samples $t$-test for each musical condition. Pearson's correlations were computed to investigate the relationship between all outcome measures for each condition. A Chi-squared analysis was used to investigate in which condition participants found easiest to tolerate pain. Effect sizes are reported as partial eta-squared and Cronbach's alpha was used to assess internal consistency for the standardized questionnaires (GSE, STAI, SF-MPQ). 


\section{Results}

\section{Baseline Scores and Internal Consistency}

No participants reported baseline pain scores on the Short-form McGill Pain Questionnaire-2 (SF-MPQ), indicating that no participants experienced pre-existing pain. Baseline NRS anxiety was marginal, $M=1.88 . S D=2.03$; and state and trait anxiety scores were low, $M_{\text {state }}=37.05, S D=0.30 ; M_{\text {trait }}=40.00, S D=12.20$. Participants showed high levels of general self-efficacy, $M=32.29, S D=4.89$. Cronbach's alpha showed internal consistency was high and representative of population and questionnaire norms for all standardized questionnaires, SF-MPQ $\alpha=.73$; GSE $\alpha=.89$; STAI $\alpha=.95$.

\section{Music Ratings}

For Familiarity, happy music was rated as more familiar than sad music, $t(40)=$ 2.57, $p=.01, \eta_{\mathrm{p}}{ }^{2}=.06$. No further significant differences were found, suggesting relaxing music was comparably familiar to happy and sad music. Descriptive statistics are reported in Table 1. For likeability, happy and relaxing music selections were liked more than sad music, $t(40)=2.96, p s<.005$. For emotion induced by the music, each song strongly induced the desired emotion ( $p s<.001$, see Figure 1 ) during the trial.

Insert Table 1. Paired samples t-test results checking familiarity, likeability and emotions induced by each song provided by the participants

Insert Figure 1. Level of emotions induced by each type of music 


\section{Primary Outcome Measures}

For Pain Tolerance, a sphericity-assumed ANOVA indicated a significant main effect of music condition, $F(3,120)=8.36, p<.001, \eta_{\mathrm{p}}{ }^{2}=.17$. Bonferroni pairwise comparisons revealed that the Pain Tolerance scores from the no music condition differed significantly from all other conditions (see Table 2 and Figure 2 for details) therefore pain tolerance was enhanced when listening to music compared with no music, $p s<.001$. All musical valences, however, were comparably effective in enhancing pain tolerance over no music.

Insert Table 2. Bonferroni pairwise comparisons on primary outcome measures

Insert Figure 2. Mean performance for pain tolerance and time estimates of perception of pain tolerance.

For Pain Intensity, a sphericity-assumed ANOVA indicated there was a significant main effect of music condition, $F(3,120)=3.09, p=.030, \eta_{\mathrm{p}}{ }^{2}=.07$. Bonferroni pairwise comparisons indicated that the only significant difference was between the no music condition and the relaxing music condition (see Table 2). Pain intensity was higher when listening to no music compared with listening to relaxing music $(p=.042)$, but otherwise pain intensity was similar across all other music conditions.

A series of paired samples t-tests were conducted to see how Perceived Pain 
Tolerance (PPT) compared with Pain Tolerance (PT) within each music condition. It was found that PPT differed from actual PT in all music conditions (See Table 3), with PPT lower than PT. A repeated measures ANOVA on PPT revealed a significant main effect of music condition, $F(3,120)=3.72, p=.015, \eta_{\mathrm{p}}^{2}=.09$. Bonferroni pairwise comparisons indicated that happy music enabled people to feel they could tolerate pain longer in comparison with no music $(p=.031)$.

Insert Table 3. Paired t-tests investigating participant perceptions of time

A chi-squared analysis found that participants considered relaxing music most beneficial for their ability to tolerate pain $\left(\chi^{2}=30.51, p<.001\right)$. Two participants voted for the no music condition, twelve voted for the happy music condition, three voted for the sad music condition, and twenty four voted for the relaxing music.

\section{Secondary Outcome Measures}

For Distraction, a Huynh-Feldt ANOVA indicated that there was a significant main effect of music condition, $F(2.56,102.54)=9.43, p<.001, \eta_{\mathrm{p}}{ }^{2}=.19$. Bonferroni post-hoc comparisons demonstrated that happy and relaxing music induced the highest distraction scores (see Table 4; ps $<.001$ ).

For Perceived Control of Pain, there was a main effect of music condition, $F(3$, 120) $=4.76, p=.004, \eta_{\mathrm{p}}{ }^{2}=.106$. Bonferroni pairwise comparisons demonstrated happy music and relaxing music were advantaged over no music. Additionally, happy music improved perceptions of pain control to a greater extent than sad music. This indicates 
that when listening to happy or relaxing music, participants had felt they were enhancing their ability to control their pain, whereas with sad or no music, perceived control was not improved.

Anxiety was also impacted by the type of music listened to, $F(3,120)=8.28, p<$ $.001, \eta_{\mathrm{p}}{ }^{2}=.17$. Bonferroni pairwise comparisons (Table 4) revealed that relaxing music was most effective at reducing anxiety when in comparison with sad music or no music, ps $<.001$.

Insert Table 4. Pairwise Comparisons of Secondary Outcome Measures

\section{Correlations between Outcome Measures}

Pearson's correlations were computed for all outcome variables within each music type. Specific results are shown in Table 5. Pain-related variables demonstrated that there were negative relationships between Pain Intensity and Pain Tolerance and Pain Intensity and Pain Control, suggesting that higher intensities of pain are more difficult to tolerate and participants rating their pain intensity highly considered themselves to be less in control of their pain across all conditions.

All conditions showed a positive relationship between Pain Tolerance and Pain Control, with the strongest correlation evident in the happy music condition, and the weakest relationship in the no music condition. Sad music also promoted this relationship to a greater extent than relaxing music. Similarly, for the no music and happy music conditions there were negative relationships between Anxiety and Pain Tolerance, such that higher levels of anxiety were related to lower levels of pain tolerance. Happy, sad 
and no music conditions are also positively correlated with Pain intensity and Anxiety, suggesting that higher levels of pain intensity were related to higher levels of anxiety. Relaxing music showed no correlations between Pain Tolerance or Pain Intensity and Anxiety, potentially reflecting the greater ability of relaxing music to reduce anxiety and pain intensity in this study.

For Distraction, there were positive relationships between higher levels of distraction and greater feelings of control over pain for all conditions. All music conditions showed moderate relationships, and music was more effective than no music, reflected in stronger correlations. This relationship was also comparable to that between Distraction ratings and Perceived Pain Tolerance time estimates, suggesting that higher levels of distraction enabled participants to feel they could tolerate their pain for longer. Those who were able to tolerate pain for longer also were more accurate in their time estimates of Perceived Pain Tolerance. The relationship between distraction and Pain Tolerance or Perceived Pain Tolerance was only evident in music conditions.

In relation to time estimations, Pain Tolerance and Perceived Pain Tolerance were investigated. Participants who were able to control their pain well also judged that they had been able to cope with their pain for a longer amount of time, and this was strongly evident in all conditions.

\section{Discussion}

This study investigated the role of participant-selected, preferred happy, sad and relaxing music on cold pressor pain, and time estimates. Happy, sad and relaxing music affected pain variables differentially, with brief physiological and psychological benefits 
demonstrated in response to listening to happy and/or relaxing music. Looking first at happy music, participants felt that happy music enhanced the amount of time they could tolerate pain to the greatest extent, strengthening their perceptions of pain control. Relaxing music was the only musical valence to affect the sensory dimension pain through reduced pain intensity, in comparison with no music. Relaxing music also reduced anxiety to a greater extent than sad or no music, and was participants' preferred valence for use during the cold pressor test, as they reported feeling that relaxing music was most beneficial for passing the time when in pain. Relaxing music mediated the relationship between anxiety and pain tolerance or pain intensity, proving more beneficial than other musical valences. Both happy and relaxing music conditions facilitated distraction from pain for participants. Sad music showed no additional benefit over no music other than those demonstrated by all musical valences. Indeed, sad music was found to reduce perceived control over pain in a comparable way to no music at all.

Music of all valences supported participants in increasing pain tolerance when compared with no music. Similarly, all music speeded the passing of time via changes in perceived pain tolerance, expressed through retrospective judgements of time passing: perceived pain tolerance was consistently lower than actual pain tolerance, suggesting participants felt time had passed more quickly than in reality. Strength of distraction was fundamental as with greater distraction, perceptions of pain tolerance increased, demonstrating that distraction was beneficial for enhancing internal locus of control, and all musical valences enhanced distraction. In general, pain tolerance was strongly negatively related to pain intensity, therefore as pain sensation increased pain tolerance decreased, but pain tolerance and pain control were positively related, suggesting that 
enhancing pain tolerance has a global impact on measures of pain self-management.

Previous research has shown that happy music enhances pain tolerance better than sad music (Tang et al., 2008). Additionally, Roy et al (2008) found that pleasant music significantly supported pain management when compared with unpleasant music. Within the classical music genre only, Silvestrini, Piguet, Cedraschi and Zentner (2013) found that pleasant classical music increased pain tolerance and decreased pain ratings over unpleasant classical music or silence. In adding greater nuance to the investigation of valence and preference, the current study demonstrated that the mechanisms of enhancements in analgesia-related outcomes are more complex. If the music used by the listener is preferred, familiar and strongly liked, happy and relaxing music function differently: happy music improves perceived pain tolerance when measured through time estimates, but relaxing music reduces pain intensity and anxiety, and is the participantpreferred choice for pain management in this study. Sad music is not advantageous for tolerance or coping with pain. By contrast, happy music and relaxing music help with distraction from pain and perceived control over pain.

Relaxing music was found to reduce pain intensity in this study, but happy music did not generate this effect. Reduced pain intensity has been found in many studies investigating music-induced analgesia (see Cepeda, Carr, Lau, \& Alvarez, 2006; Finlay \& Rogers, 2014), with preferred music showing the greatest benefits to patients (Mitchell et al., 2006). However, why the benefits of relaxing music did not parallel those shown by happy music is challenging - in previous research, pain intensity decreased with a positive stimulus (e.g. happy music; Tang et al., 2008; van Laarhoven et al., 2012). Since participants liked all music in this study, it is possible that some emotional transference 
existed between relaxing and happy music, with the relaxing music inducing positive emotions in addition to unique feelings of relaxation (Tang et al., 2008). However, it could be argued that the different findings between happy and relaxing music could be a results of a time perception mechanism: participants perceived time passing differently when listening to happy and relaxing music.

Participants estimated that with happy music they could tolerate pain for longer, but when asked to select their preferred music for pain management, they chose relaxing music. It may be that the relaxing music is cognitively biased as it is strongly associated with therapeutic practices (e.g. massage) and relaxation-states (R-States; see Smith \& Joyce, 2004). Chavez (2004) found that when asked to recall the amount of time spent relaxing, participants estimated that time passed quicker (fewer seconds), but perceived that time period as having passed by more slowly. Chavez argues that this outcome is related to memory: when relaxing, movement is limited, and individuals estimate time by remembering the number of actions and movements they performed. The more anxious an individual is, the more intruding thoughts they have (Alwahhabi, 2003). When anxiety is reduced, the mind becomes less busy (Reinecke, Hoyer, Rinck \& Becker, 2013). In this study, relaxing music decreased anxiety the most; when recalling the passage of time, participants may therefore have been influenced to a lesser extent by pain-related, busy or negative thought activity. As a result of the relaxing music, there may have been fewer thoughts/actions to remember and participants therefore estimated time differently. The therapeutic cognitive bias combined with changes in memory for thoughts/actions may be why participants selected the relaxing music as more advantageous than the happy music. Further research is needed to investigate pain-related thought/activity frequency when 
listening to music, potentially using a think-aloud protocol.

In this study, pain tolerance and perceived pain tolerance were both enhanced by music listening. In general, all participants who were able to tolerate pain for longer lengths of time also judged the passing of time to be elongated, suggesting that they not only could cope, but felt they were coping with pain. Throughout the study, pain tolerance and pain control were strongly correlated, affected by music of all valences and were inversely related to pain intensity. This suggests that affective components of pain were fundamentally related to time perception and to enhancing the pain-related locus of control (Coughlin, Badura, Fleischer, \& Guck, 2000). It is the ability to tolerate pain for longer that is most applicable in a clinical context. Research into so-called 'Third Wave' behavioral therapies has suggested that cognitive restructuring or behavioral change is less effective for long-term pain management than accepting and learning to live with pain, in spite of pain - a therapeutic stance known as Acceptance and Commitment Therapy (ACT; Gaudiano, 2006). That music has the ability to enhance pain tolerance is potentially more powerful than associated reductions in pain intensity as it supports the pain sufferer in their daily living in spite of pain. The anxiolytic function of music listening enhances acceptance and living alongside pain. Lauche et al (2013) and Mohammadi et al (2013) suggest that through relaxation, pain-related distress is reduced. This is seen in this study, as anxiety scores were lowest during the relaxing music condition.

In the current study, sad music supported enhanced pain tolerance, though its impact was evidently less effective for pain management than happy and relaxing music. However, no evidence was found to suggest that preferred sad music exacerbates pain. 
Ladinig and Schellenberg (2012) argue that individuals generally prefer listening to music that makes them feel happy, rather than music that makes them feel sad. In the context of passing the time when in pain, this is modeled by the current results; participants liked sad music the least. However, Schellenberg et al. (2008) suggests that individuals like to listen to sad music when they themselves are feeling stressed or upset - potentially emotions that are induced by pain. This way, individuals in a negative mood can relate their feelings expressed in the sad song through catharsis.

The current study used the cold pressor test to induce experimental pain and it is possible that the need for sad music to initiate catharsis was lesser due to the non-clinical nature of the pain. Future research should therefore aim to extend this study with a clinical population and with chronic pain to assess the value of music-induced catharsis in greater depth. Schellenberg et al (2008) argued that participants prefer to listen to music that relates to their current mood. So, influencing mood at the beginning of the study might result in variability in the pain management that is promoted. This research did not assess pre-existing mood state at the outset of the study, and it may be that the mood of the listener may have influenced their receptivity to the musical stimulus when used for pain management. Future research should aim to include a mood screening in the test battery, used before and throughout the research design.

The current research used an initial no-music condition as a baseline trial. It is possible that the presentation order of musical stimuli could be fully randomised, including the no music condition, to minimise potential habituation effects. This, however, risks the carry-forward effect of music in the context of activating involuntary musical imagery or 'ear-worms' that are internalised during the music conditions and 
subsequently used during the no-music condition (Hyman et al., 2015; Williamson et al., 2012; Williams, 2015). Future research could aim to investigate carry-forward effects of music listening for pain management, following Finlay (2013). Similarly it is possible that demand characteristics may have arisen due to the differentiation between no music and music conditions. Whilst efforts were made to minimise this through randomising music presentation order, future research could request prospective and retrospective expectancy ratings to control for possible participant-initiated expectancy effects. Time perception ratings may also have been affected by pre-existing knowledge of track lengths, though efforts were made to reduce potential bias by removing all time-keeping devices from participants and the laboratory context.

The current study demonstrated that music continues to confirm its utility for pain management, particularly in the context of enhancing pain tolerance. Preferred music of different valence impacts positively upon pain intensity, anxiety, tolerance and distraction in different ways. Both happy and relaxing music supports the passing of time when in pain, however, relaxing music appears to have a wider ability to support self-management of pain. The current study has shown that all music is advantaged over no music in its ability to extend the amount of time people are able to tolerate pain, suggesting that it has value in supporting patients in living with daily pain in the context of third wave behavioral therapies. 


\section{References}

Andersson, H. I., Ejlertsson, G., Leden, I., \& Scherstén, B. (1999). Impact of chronic pain on health care seeking, self care, and medication. Results from a population-based Swedish study. Journal of Epidemiology and Community Health, 53(8), 503-509. doi:10.1136/jech.53.8.503

Abu-Saad, H. H. (2010). Chronic pain: a review. The Lebanese Medical Journal. 58(1), $21-27$.

Alwahhabi, F. (2003). Anxiety Symptoms and Generalized Anxiety Disorder in the Elderly: A Review. Harvard Review of Psychiatry. 11(4), 180-93.

Barnes, L. B., Harp, D., \& Jung, W. (2002). Reliability Generalization of Scores on the Spielberger State-Trait Anxiety Inventory. Educational \& Psychological Measurement. 62(4), 603 .

Bell, K. M., \& Meadows, E. A. (2013). Efficacy of a brief relaxation training intervention for pediatric recurrent abdominal pain. Cognitive and Behavioral Practice. 20(1), 81-92.

Cassidy, G. G., \& MacDonald, R. R. (2010). The effects of music on time perception and performance of a driving game. Scandinavian Journal of Psychology. 51(6), 455-464. 
Cepeda, M. S., Carr, D. B., Lau, J., \& Alvarez, H. (2006). Music for pain relief. Cochrane Database of Systematic Reviews (Online), (2), CD004843. doi:10.1002/14651858.CD004843.pub2

Chavez, B. (2003). Effects of stress and relaxation on time perception. Unpublished Ph.D. Thesis. Uniformed Services University of the Health Sciences.

Chen, Y., \& Francis, A. P. (2010). Relaxation and imagery for chronic, nonmalignant pain: Effects on pain symptoms, quality of life, and mental health. Pain Management Nursing. 11(3), 159-168.

Cordell, W. H., Keene, K. K., Giles, B. K., Jones, J. B., Jones, J. H., \& Brizendine, E. J. (2002). The high prevalence of pain in emergency medical care. American Journal of Emergency Medicine. 20(3), 165-169.

Coughlin, A. M., Badura, A. S., Fleischer, T. D., \& Guck, T. P. (2000). Multidisciplinary treatment of chronic pain patients: Its efficacy in changing patient locus of control. Archives of Physical Medicine and Rehabilitation, 81(6), 739-740. http://doi.org/10.1016/S0003-9993(00)90103-5

Davis, W. B., \& Thaut, M. H. (1989). The influence of preferred relaxing music on measures of state anxiety, relaxation, and physiological responses. Journal of Music Therapy, 26(4), 168-187. 
Droit-Volet, S., Bigand, E., Ramos, D., \& Bueno, J. (2010). Time flies with music whatever its emotional valence. Acta Psychologica. 135(2), 226-232.

Finlay, K. A. (2013). Music-induced analgesia in chronic pain: Efficacy and assessment through a primary-task paradigm. Psychology of Music, 42(3), 325-346. http://doi.org/10.1177/0305735612471236

Finlay, K. A., \& Rogers, J. (2014). Maximizing self-care through familiarity: The role of practice effects in enhancing music listening and progressive muscle relaxation for pain management. Psychology of Music, 43(4), 511-529.

http://doi.org/10.1177/0305735613513311

Gaudiano, B. A. (2006). The "Third Wave" Behavior Therapies in Context: Review of Hayes et al.'s (2004) Mindfulness and Acceptance: Expanding the Cognitive-Behavioral Tradition and Hayes and Strosahl's (2004) A Practical Guide to Acceptance and Commitment Therapy. Cognitive and Behavioral Practice, 13(1), 101-104. http://doi.org/10.1016/j.cbpra.2006.01.002

George, J. M., \& Brief, A. P. (1992). Feeling good-doing good: A conceptual analysis of the mood at work-organizational spontaneity relationship. Psychological Bulletin. 112(2), 310-329. 
Georgel, J. M., \& Jones, G. R. (1997). Experiencing Work: Values, Attitudes, and Moods. Human Relations. 50(4), 393-416.

Girden, E. (1992). ANOVA: Repeated measures. Newbury Park, CA: Sage.

Good, M. (1996). Effects of relaxation and music on postoperative pain: a review. Journal of Advanced Nursing. 24, 905-14.

Good, M., Stanton-Hicks, M., Grass, J. A., Cranston, A. G., Choi, C., Schoolmeesters, L. J., et al. (1999). Relief of postoperative pain with jaw relaxation, music and their combination. Pain. 81, 163-72.

Hargreaves, D. J., \& North, A. C. (1997). The social psychology of music. Oxford: Oxford University Press.

Hasselstrom J, Liu-Palmgren J, \& Rasjo-Wraak G. 2002. Prevalence of pain in general practice. Eur J Pain, 6:375-85.

Hyman, I. E., Cutshaw, K. I., Hall, C. M., Snyders, M. E., Masters, S. A., Au, V. S. K., \& Graham, J. M. (2015). Involuntary to intrusive: Using involuntary musical imagery to explore individual differences and the nature of intrusive thoughts. Psychomusicology: Music, Mind, and Brain, 25(1), 14-27. http://doi.org/10.1037/pmu0000075 
Jackson, T. D., Pope, L. E., Nagasaka, T. O., Fritch, A. L., Iezzi, T. Y., \& Chen, H. G. (2005). The impact of threatening information about pain on coping and pain tolerance. British Journal of Health Psychology, 10(3), 441-451.

Jensen, M. P., \& Karoly, P. (2001). Self-report scales and procedures for assessing pain in adults. In D. C. Turk \& R. Melzack (Eds.), Handbook of pain assessment (2nd ed., pp. 135-151). New York, NY: Guilford Press.

Juslin, P.N. \& Sloboda, J. A. (Eds.) (2009). Handbook of Music and Emotion: Theory, Research, Applications. Oxford University Press: Oxford.

Kawakami, A., Furukawa, K., Katahira, K., \& Okanoya, K. (2013). Sad music induces pleasant emotion. Frontiers in Psychology, 4. http://doi.org/10.3389/fpsyg.2013.00311

Keefe, F. J., Lumley, M., Anderson, T., Lynch, T., \& Carson, K. L. (2001). Pain and emotion: New research directions. Journal of Clinical Psychology, 57(4), 587-607. doi:10.1002/jclp.1030

Kivy, P. (1989). Sound sentiment: An essay on the musical emotions, including the complete text of The Corded Shell. Philadelphia, PA: Temple University Press.

Kivy, P. (1990). Music alone: Philosophical reflections on the purely musical experience. Ithaca, NY: Cornell University Press. 
Kivy, P. (2002). Introduction to a philosophy of music. Oxford: Clarendon Press.

Konečni, V. J. (2008). Does music induce emotion? A theoretical and methodological analysis. Psychology of Aesthetics, Creativity, and the Arts. 2, 115- 129.

Konečni, V. J., Brown, A., \& Wanic, R. A. (2008). Comparative effects of music and recalled life-events on emotional state. Psychology of Music. 36, 289- 308.

Krahé, B., \& Bieneck, S. (2012). The Effect of Music-Induced Mood on Aggressive Affect, Cognition, and Behavior. Journal of Applied Social Psychology. 42(2), 271-290.

Ladinig, O., \& Schellenberg, E. (2012). Liking unfamiliar music: Effects of felt emotion and individual differences. Psychology of Aesthetics, Creativity, And The Arts, 6(2), 146154.

Lauche, R., Materdey, S., Cramer, H., Haller, H., Stange, R., Dobos, G., \& Rampp, T. (2013). Effectiveness of Home-Based Cupping Massage Compared to Progressive Muscle Relaxation in Patients with Chronic Neck Pain-A Randomized Controlled Trial. Plos ONE. 8(6), 1-9.

Levinson, J. (1990). Music and negative emotions. In J.Levinson ( Ed.), Music, art, and metaphysics: Essays in philosophical aesthetics (pp. 306- 335). Ithaca: Cornell University Press. 
Litt, M. D. (1988). Self-efficacy and perceived control: Cognitive mediators of pain tolerance. Journal of Personality and Social Psychology, 54(1), 149-160. http://doi.org/10.1037/0022-3514.54.1.149

MacDonald, R. A. R., Miell, D., \& Hargreaves, D. J. (2002). Musical identities. Oxford: Oxford University Press.

McCaul, K. D., \& Malott, J. M. (1984). Distraction and coping with pain. Psychological Bulletin. 95(3), 516-33.

Misic, P., Arandjelovic, D., Stanojkovic, S., Vladejic, S., and Mladenovic, J. (2010). Music Therapy. European Psychiatry. 25, 839.

Mitchell, L. A., MacDonald, R. A. R., \& Brodie, E. E. (2004). Temperature and the cold pressor test. Journal of Pain, 5(4), 233-237.

Mitchell, L. A., \& MacDonald, R. A. R. (2006). An experimental investigation of the effects of preferred and relaxing music listening on pain perception. Journal of Music Therapy, 43(4), 295-316.

Mitchell, L. A., MacDonald, R. A. R., \& Brodie, E. E. (2006). A comparison of the effects of preferred music, arithmetic and humour on cold pressor pain. European 
Journal of Pain, 10(4), 343-351.

Mohammadi, F. F., Rafii, F., \& Jamshidi, O. R. (2013). The effect of jaw relaxation on pain anxiety during burn dressings: Randomised clinical trial. Burns (03054179). 39(1), 61-67.

Polaino-Lorente, A. M. (1977). Neurosis, relaxation, and sense of time: An experimental study. Revista De Psicología General Y Aplicada. 32(144), 29-39.

Reinecke, A., Hoyer, J., Rinck, M., \& Becker, E. S. (2013). Cognitive-behavioural therapy reduces unwanted thought intrusions in generalized anxiety disorder. Journal Of Behavior Therapy \& Experimental Psychiatry. 44(1), 1-6.

Rejeh, N., Heravi-Karimooi, M., Vaismoradi, M., \& Jasper, M. (2013). Effect of systematic relaxation techniques on anxiety and pain in older patients undergoing abdominal surgery. International Journal of Nursing Practice. 19(5), 462-470.

Roy, M., Peretz, I., \& Rainville, P. (2008). Emotional valence contributes to musicinduced analgesia. Pain. 134(1-2), 140-147.

Schellenberg, E. G., Peretz, I., \& Vieillard, S. (2008). Liking for happy- and sadsounding music: Effects of exposure. Cognition and Emotion, 22, 218- 237. 
Schwarzer, R., \& Jerusalem, M. (1995). Generalized Self-Efficacy scale. In J. Weinman, S. Wright, \& M. Johnston, Measures in health psychology: A user's portfolio. Causal and control beliefs (pp. 35-37). Windsor, UK: NFER-NELSON.

Silvestrini, N., Piguet, V., Cedraschi, C., \& Zentner, M. R. (2011). Music and Auditory Distraction Reduce Pain: Emotional or Attentional Effects? Music and Medicine, 3(4), 264-270. http://doi.org/10.1177/1943862111414433

Smith, J. C., \& Joyce, C. A. (2004). Mozart versus New Age Music: Relaxation States, Stress, and ABC Relaxation Theory. Journal of Music Therapy, 41(3), 215-224. http://doi.org/10.1093/jmt/41.3.215

Sun, M., Hsieh, C., Cheng, Y., Hung, H., Li, T., Yen, S., \& Huang, I. (2010). The Therapeutic Effects of Acupuncture on Patients with Chronic Neck Myofascial Pain Syndrome: A Single-Blind Randomized Controlled Trial. American Journal Of Chinese Medicine. 38(5), 849-859.

Spielberger, C. D., Gorsuch, R. C., Lushene, R. E., Vagg, P. R., \& Jacobs, G. A. (1983). Manual for the State-Trait Anxiety Inventory. Palo Alto: Consulting Psychologists Press.

Tan, X., Yowler, C. J., Super, D. M., \& Fratianne, R. B. (2012). The interplay of preference, familiarity and psychophysical properties in defining relaxation music. Journal of Music Therapy. 49(2), 150-179. 
Tang, N. Y., Salkovskis, P. M., Hodges, A., Wright, K. J., Hanna, M., \& Hester, J. (2008). Effects of mood on pain responses and pain tolerance: An experimental study in chronic back pain patients. Pain. 138(2), 392-401.

Turner, J. A., Jensen, M. P., \& Romano, J. M. (2000). Do beliefs, coping, and catastrophizing independently predict functioning in patients with chronic pain? Pain, $85(1), 115-125$.

Tjakke, G. E., Reinders, J., Tenvergert, E. M., \& Stegenga, B. (2010). TMD pain: the effect on health related quality of life and the influence of pain duration. Health and Quality of Life Outcomes. 8(46).

Vaajoki, A., Pietilä, A., Kankkunen, P., \& Vehviläinen-Julkunen, K. (2012). Effects of listening to music on pain intensity and pain distress after surgery: an intervention. Journal of Clinical Nursing. 21(5/6), 708-717.

van Laarhoven, A. M., Walker, A. L., Wilder-Smith, O. H., Kroeze, S. S., van Riel, P. M., van de Kerkhof, P. M., \& ... Evers, A. M. (2012). Role of induced negative and positive emotions in sensitivity to itch and pain in women. British Journal Of Dermatology. 167(2), 262-269.

Vuoskoski, J. K., \& Eerola, T. (2012). Can sad music really make you sad? Indirect 
measures of affective states induced by music and autobiographical memories.

Psychology of Aesthetics, Creativity, And The Arts, 6(3), 204-213.

Williams, T. I. (2015). The classification of involuntary musical imagery: The case for earworms. Psychomusicology: Music, Mind, and Brain, 25(1), 5-13. http://doi.org/10.1037/pmu0000082

Williamson, V. J., Jilka, S. R., Fry, J., Finkel, S., Mullensiefen, D., \& Stewart, L. (2012). How do "earworms" start? Classifying the everyday circumstances of Involuntary Musical Imagery. Psychology of Music, 40(3), 259-284. http://doi.org/10.1177/0305735611418553

Wohlheiter, K. A., \& Dahlquist, L. M. (2013). Interactive versus passive distraction for acute pain management in young children: The role of selective attention and development. Journal of Paediatric Psychology. 38(2), 202-212.

Wright, T., \& Raudenbush, B. (2010). Interaction Effects of Visual Distractions, Auditory Distractions and Age on Pain Threshold and Tolerance. North American Journal of Psychology. 12(1), 145-157.

Yamada, Y., \& Kawabe, T. (2011). Emotion colors time perception unconsciously. Consciousness \& Cognition. 20(4), 1835-1841. 
Zhao, H., \& Chen, A. C. N. (2009). Both Happy and Sad Melodies Modulate Tonic Human Heat Pain. The Journal of Pain, 10(9), 953-960.

http://doi.org/10.1016/j.jpain.2009.03.006 
Figure 1: Average familiarity and likeability scores for participant-provided music type

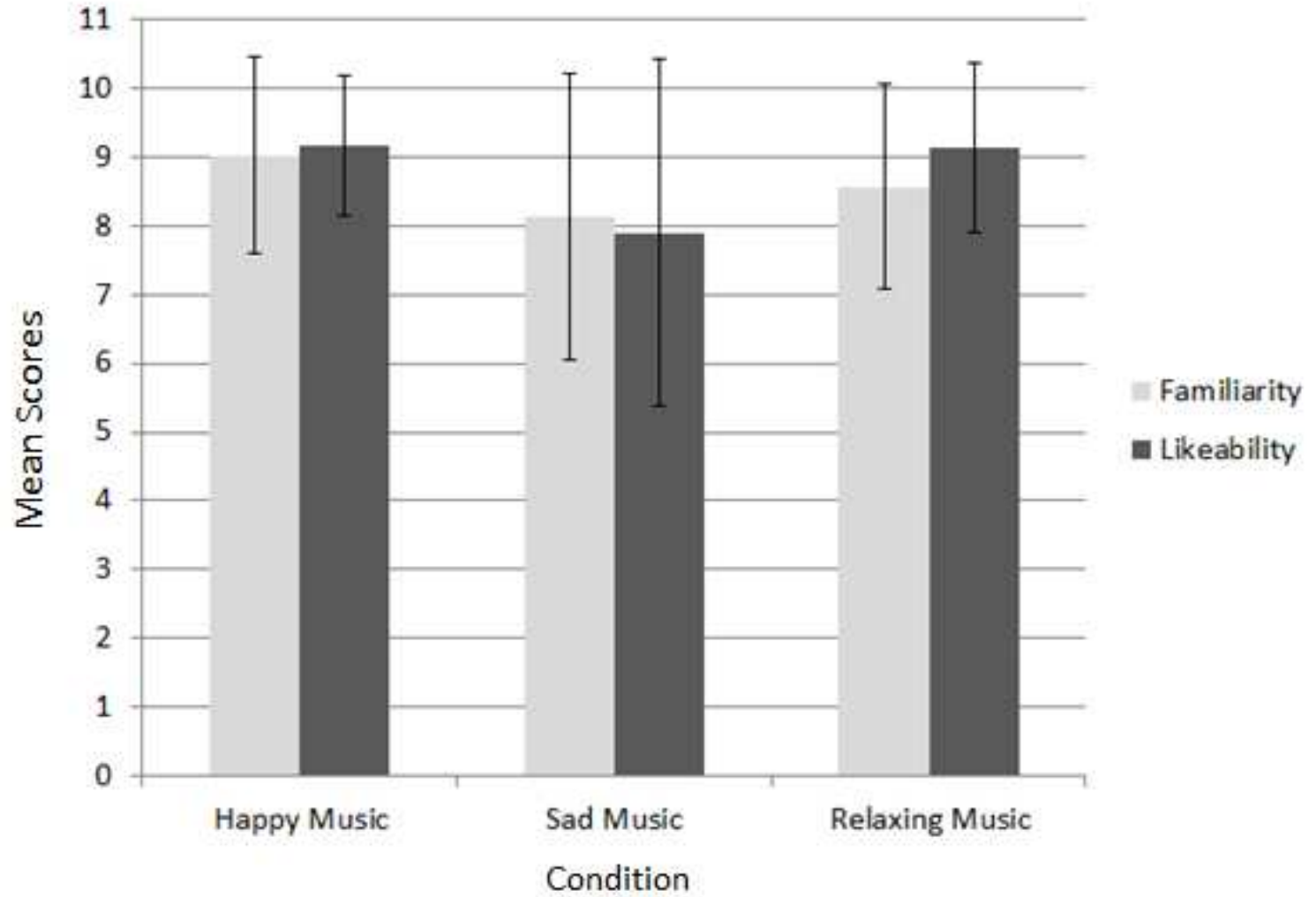

Note: Error bars show $\pm 1 \mathrm{SD}$ 
Figure 2: Level of emotions induced by each type of music

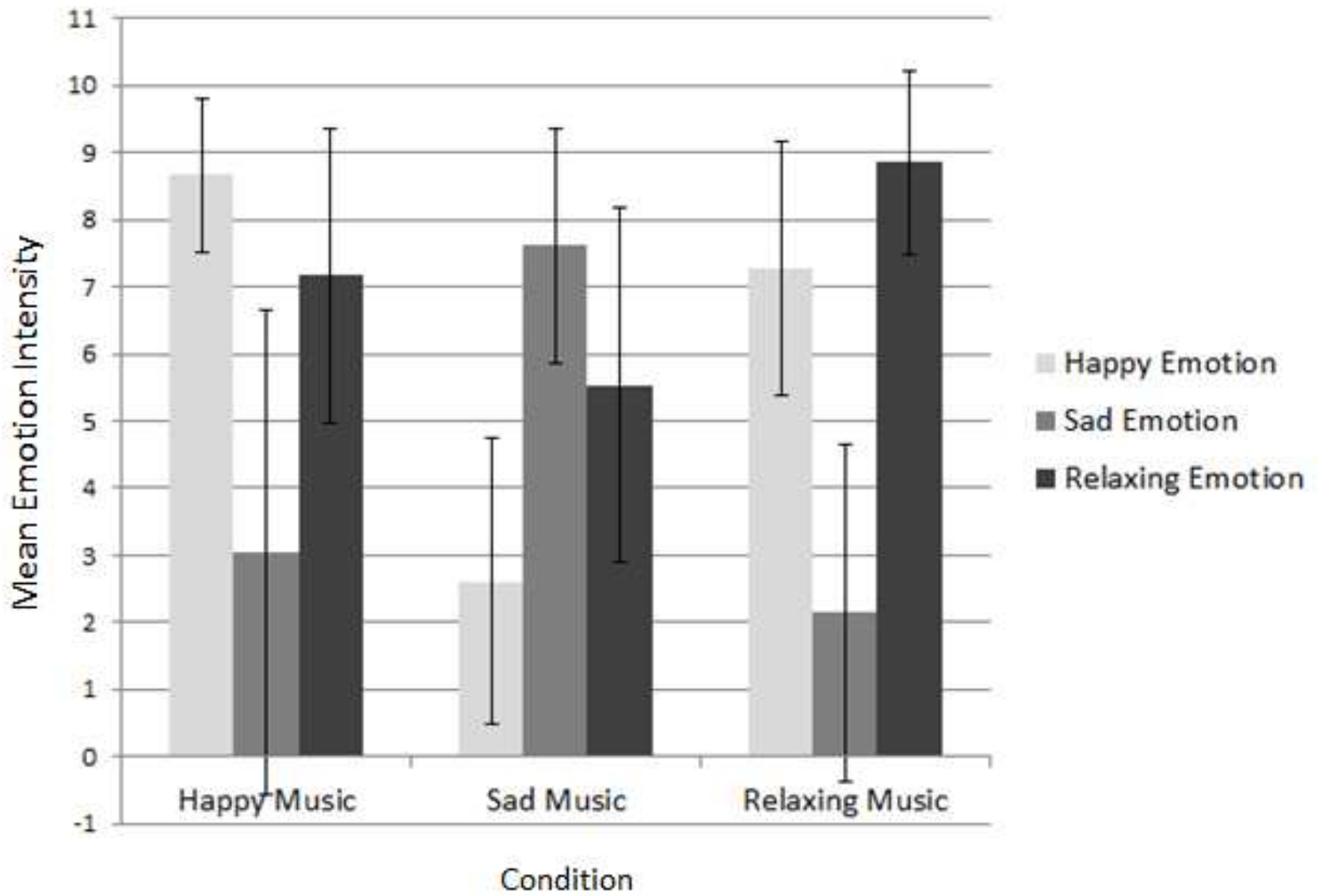

Note: Error bars show $\pm 1 \mathrm{SD}$ 
Table 1: Paired samples t-test results checking familiarity, likeability and emotions induced by each song provided by the participants.

\begin{tabular}{|c|c|c|c|c|c|c|}
\hline & $\mathrm{N}=41$ & Mean & $\begin{array}{c}\text { Std. } \\
\text { Deviation }\end{array}$ & $\mathbf{t}$ & df & $\mathbf{p}$ \\
\hline \multirow{3}{*}{ Familiarity } & HS - SS & 0.902 & 2.245 & 2.574 & 40 & $0.014^{*}$ \\
\hline & HS - RS & 0.463 & 1.485 & 1.998 & 40 & 0.053 \\
\hline & $\mathbf{S S}$ - RS & -0.439 & 2.377 & -1.182 & 40 & 0.244 \\
\hline \multirow{3}{*}{ Likeability } & HS - SS & 1.244 & 2.691 & 2.960 & 40 & $0.005^{* *}$ \\
\hline & HS - RS & 0.024 & 1.369 & 0.114 & 40 & 0.910 \\
\hline & SS - RS & -1.220 & 2.903 & -2.690 & 40 & $0.010^{*}$ \\
\hline \multirow{2}{*}{$\begin{array}{c}\text { Emotions } \\
\text { Induced by } \\
\text { Happy } \\
\text { Music }\end{array}$} & HE - SE & 5.610 & 3.748 & 9.585 & 40 & $<0.000 * * *$ \\
\hline & HE - RE & 1.488 & 2.325 & 4.097 & 40 & $<0.000 * * *$ \\
\hline \multirow{2}{*}{$\begin{array}{l}\text { Emotions } \\
\text { Induced by } \\
\text { Sad Music }\end{array}$} & SE - HE & 5.000 & 3.225 & 9.928 & 40 & $<0.000 * * *$ \\
\hline & SE - RE & 2.073 & 2.970 & 4.470 & 40 & $<0.000 * * *$ \\
\hline $\begin{array}{l}\text { Emotions } \\
\text { Induced by }\end{array}$ & RE - HE & 6.537 & 3.195 & 13.102 & 40 & $<0.000^{* * * *}$ \\
\hline $\begin{array}{l}\text { Relaxing } \\
\text { Music }\end{array}$ & $\mathbf{R E}-\mathbf{S E}$ & 1.415 & 1.774 & 5.105 & 40 & $<0.000 * * *$ \\
\hline
\end{tabular}

$$
\begin{aligned}
& \text { HS = Happy Song } \quad * \quad \mathrm{p}<0.05 \\
& \mathrm{SS}=\text { Sad Song } \quad * * \quad \mathrm{p}<0.01 \\
& \text { RS }=\text { Relaxing Song } \quad * * * \mathrm{p}<0.001 \\
& \mathrm{HE}=\text { Happy Emotion } \\
& \mathrm{SE}=\mathrm{Sad} \text { Emotion } \\
& \mathrm{RE}=\text { Relaxing Emotion }
\end{aligned}
$$


Table 2: Bonferroni pairwise comparisons of IVs within each audio condition.

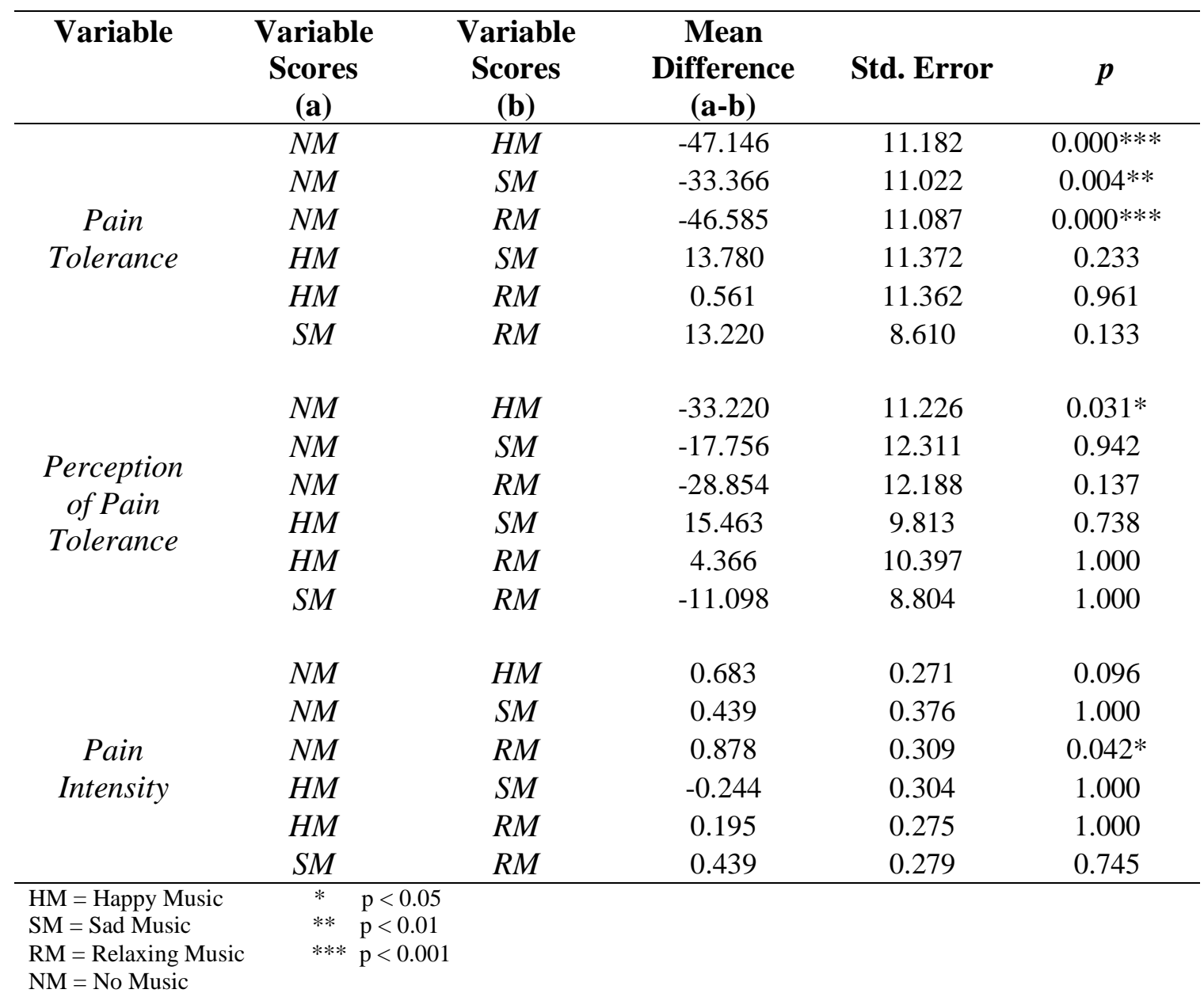

Table 3: Paired t-test investigating participants perception of time during pain.

\begin{tabular}{cccccccc}
\hline \multicolumn{2}{c}{ PT } & \multicolumn{2}{c}{ PPT } \\
\hline & Mean & $\begin{array}{c}\text { Std. } \\
\text { Deviation }\end{array}$ & Mean & $\begin{array}{c}\text { Std. } \\
\text { Deviation }\end{array}$ & t & df & $\boldsymbol{p}$ \\
\hline NM & 94.71 & 91.258 & 77.90 & 99.695 & 1.881 & 40 & 0.067 \\
HM & 141.85 & 98.466 & 111.12 & 91.410 & 4.143 & 40 & $0.000^{* * *}$ \\
SM & 128.07 & 96.633 & 95.66 & 90.612 & 3.778 & 40 & $0.001^{* *}$ \\
RM & 141.29 & 97.834 & 106.76 & 90.546 & 4.030 & 40 & $0.000^{* * *}$ \\
\hline
\end{tabular}

$\mathrm{PT}=$ Pain Tolerance

$\mathrm{PPT}=$ Perception of Pain Tolerance

$\mathrm{HM}=$ Happy Music

$\mathrm{SM}=$ Sad Music

$\mathrm{RM}=$ Relaxing Music

$$
\begin{array}{ll}
* & \mathrm{p}<0.05 \\
* * & \mathrm{p}<0.01 \\
* * * & \mathrm{p}<0.001
\end{array}
$$


$\mathrm{NM}=$ No Music

Table 4: Frequency of easiest trial chosen.

\begin{tabular}{cc}
\hline Audio Conditions & $\begin{array}{c}\text { Times Chosen As } \\
\text { Easiest Trial }\end{array}$ \\
\hline No Music & 2 \\
Happy Music & 12 \\
Sad Music & 3 \\
Relaxing Music & 24 \\
Total & 41 \\
\hline
\end{tabular}

Table 5: Bonferroni pairwise comparisons of IVs of each audio condition.

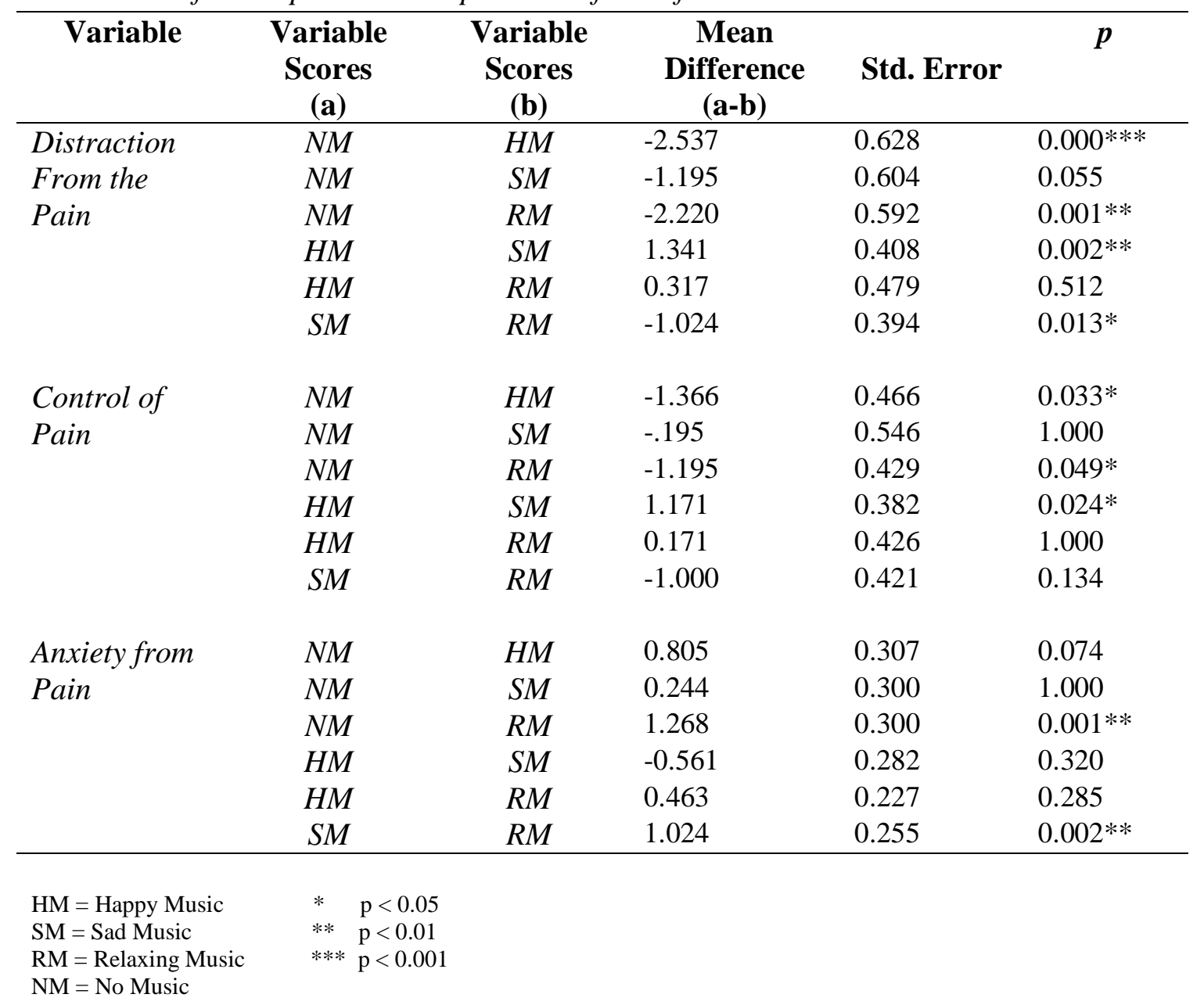

